\title{
On Building SSR Teaching Model of the Logistics Professional Based on Cultivating the Ability of Innovation
}

\author{
Weixia Yang \\ School of business \\ Xian International University \\ Xi'an, China \\ wxyang741117@163.com
}

Keywords: innovation ability, applied undergraduate, logistics professional, SSR mode

\begin{abstract}
In this paper, the author adopts SSR create education mode for the practice of innovation entrepreneurship education according to the principle of creation education, based on the concept of applied education and the characteristics of logistics professional students, in order to explore the teaching mode of the applied undergraduate colleges and universities, to promote Chinese logistics professional students' innovative ability.
\end{abstract}

\section{Introduction}

Since our country have expansed the enrollment in 1999, there are more than 200 colleges and universities to open logistics management, and they have raised nearly 100000 students. With the number of college graduates increasing, the employment rate of college graduates is decreasing. It makes the employment matter since practical demand for logistics professional is stronger and Students' training,the cultivation effect of the students is not good.

In the notice on doing well the work of college graduates' employment, Ministry of education pointed out that we must highlight the promoting the employment of university graduates in the important position, the local universities should widely carry out creative education and practice, and integrate the innovation entrepreneurship education into the whole process of teaching and personnel training. So we may actively cultivate the students' pioneering consciousness, innovation spirit, and improve the ability of entrepreneurship. This is compatible with the development goal that builds a well-off society in an all-round way in China, such as "into an innovative country" and "innovation personnel training level increased significantly".

But the cultivation and improvement of the college students' innovative ability has been insufficient only by the original traditional education mode, it is especial that the teacher guiding Venture project design can be realized by general classroom education. If we will use new education mode In the private university logistics professional education ,it will deepen the reform of higher education to a certain extent, help students to break the traditional mode of thinking, and help teachers to break the traditional teaching methods. Finally, it will promote close cooperation and communication between teachers and students, help students to improve innovation ability and let teachers to change teaching idea and method, to improve their teaching level and innovation ability, thus it ensure the quality of the applied undergraduate education, to achieve the fundamental goal of cultivating innovative entrepreneurial talent. 


\section{Logistics Professional Students Creative Ability Training Needs}

A. Existing education requires students to possess the innovation ability

In the "Some opinions on comprehensively improving the teaching quality of Applied Undergraduate Education ",the ministry of education pointed out that the applied undergraduate students' professional ability training goal is that in the light of the characteristics of applied undergraduate colleges and universities students, we should cultivate the students' social adaptability, educate students to set up the concept of life-long study, to improve the ability to learn, and to learn to communicate and the team cooperation, and we should improve the students' practical ability, creative ability, employment ability and entrepreneurial ability, cultivate students as the comprehensive development of socialist builders and successors.

Existing logistics professional teaching mainly solved the general employment ability of students and part of the practical ability, and create ability and entrepreneurial ability is not enough, especially the proportion of entrepreneurship students is far from the level of the developed countries, for example students entrepreneurial ratio above $20 \%$ in American, while China is below $1 \%$. As a result, it is an important goal of modern higher education that we improve logistics professional students' innovative undertaking ability.

$B$. Innovation entrepreneurship needs more rich variety of teaching methods to achieve

To improve the logistics professional students' innovation ability, we need to match the teaching level and means. Currently we used technology of entrepreneurship education is the mainstream of the multimedia teaching, as a theory of teaching can be implemented by it, but it is is not enough to the practical subject, because that it must take the student as the center, attaches great importance to the active participation of students, help learners develop metacognitive and autonomous learning ability in the practical subject. Therefore, we need to make full use of the school's teaching resources, and make use of existing information technology, build the development of distance learning and communication platform, promote and form the innovation of teaching methods and means.

C. The existing teaching content and teaching materials is not reasonable

The current teaching content about improving the ability of innovation and entrepreneurship is not systematic, lack of pertinence, without considering the training objectives and characteristics of applied undergraduate students, let alone logistics professional teaching contents, especially the innovation of knowledge, it is not discriminated with universities and other professional, so it is not conducive to the real development of students' thinking and improve the ability of innovation owing to lacking of professional logistics and direct relevance. In addition, the knowledge taught emphasis on theory ,and no emphasis on entrepreneurship project design professional skills, entrepreneurial activities in the form of mere formalities to learn more.

$D$. It is urgent to improve the success rate of logistics professional students to start a business

The logistics professional employment situation is good, but the proportion of entrepreneurship is very low. From the survey we found that the proportion of students participate entrepreneurship is quite low in the logistics professional degree, but From the background of professional knowledge, professional logistics students are with entrepreneurial advantage, even more should have this consciousness, but the fact is not so. The main reason is that the education oriented and teaching methods. In the long term, the school invested in innovation and entrepreneurship education teachers, set the class, class size is very limited, we must change the status quo, it has become an important work in the education to cultivate students' ability of innovation and entrepreneurship, to break the traditional teaching the concepts and methods , ant to constructe the second class and third class, to ensure the quality of teaching. Let the students have more personalized space to play advantage, we will in the 
"double "Rail" education road during the occupation of personnel training, and train employment and entrepreneurial talent.

\section{Reform Ideas of SSR Creative Education Mode}

The "SSR mode" was founded by the famous Chinese educator Liu Daoyu, it is a model of creative education implemented by the university to based on the basis of the principle and characteristics of creative education. The first " $\mathrm{S}$ " is acronym of "Study indepen-dendy", which can be translated into selfstudy or independent learning which is the ways of learning by the learners themselves to complete. The second " $S$ " is the abbreviation of Seminar, it refers to a form of classroom discussion by College Students under the guidance, sometimes it also refers to the discussion course. " $\mathrm{R}$ " is the abbreviation of Research, its meaning is research and exploration. We put forward the reform thinking with the goal of entrepreneurship education and the characteristics of the students in logistics major:

E. To set up a clear goal of talent training, and converse philosophy of educationa

We should specific the talents training goal of application type undergraduate that is to improve the students' practical ability, creative ability, employability and entrepreneurship, to train Dezhitimei allround development of socialist builders and successors. We should change the education idea of traditional employment, and establish the concept of talent that is a good record entrepreneurship as the wing.

F. To introduct the ideas of creative education and applicate the model of SSR

To introduct the ideas of creative education and applicate the model of SSR is the new mode of education which developes human subjectivity and human potential. We should in-depth study the advanced education thought and explorate the existing mode of SSR creative education, so we may build the new model of entrepreneurial education of he logistics professional.

G. To integrate and utilize the existing teaching resources

At present, the school has provided many favorable conditions to innovation education and enterprise education, such as setting up special research funds construction and establishing innovation and Entrepreneurship Education Research Institute. We should has the most advantage of these hardware and software to ensure the teaching level and teaching quality.

H. To construct the new teaching mode of "combining learning and learning", which is based on entrepreneurial project

Based on the theory of SSR, we should study "integrated learning" mode, and implement innovation and entrepreneurship education to form a specific implementation plan and management methods by the combination of theoretical teaching and practical teaching, forming a entrepreneurial team and designing entrepreneurship project. At last, we summarize the teaching effectiveness, teaching experience, and extended to all logistics professional students.

\section{The Way of Constructing SSR Teaching Mode}

I. To transformate create educational theory and SSR model to practice

At first, we should change the traditional concepts of education, and advocate the culture that excellent student may start a business and the talent concept that employment oriented changes to be proud of business. We should adopt the two track education of the" employment "and" entrepreneurial ", train mass and elite talent, and forme the innovation and entrepreneurship education philosophy that entrepreneurial drives employment. We should Introduce SSR creative education mode of practical exploration, and constructing a new education mode. 
In the implementation of entrepreneurship education, we should divide into two steps: Theory teaching and Practice teaching. We implement the theory teaching through Classroom Teaching, online education and self-learning, and implement the practice teaching by designing entrepreneurial project,process guidance and achievements transformation. The theoretical teaching and The practical teaching is not completely separated, some theory will be learned in practice, and students' self-study and discussion between teachers and students conducted in class and extracurricular simultaneously. At the same time, teachers and students in teaching practice jointly explore research results.

J. To constructe the first class of theoretical study and professional skills training

In the process of construction the first class of theoretical study and professional skills training, on the one hand,we should do talent evaluation and characteristics of analysis for students, do the analysis of the existing teaching materials, and rewrite the complete system of curriculum and teaching outline in order to write new special teaching materials for the teaching reform. At last, we should form the research report by repeated attempts and innovation in the practice of teaching. On the other hand, we should introduce good game items such as cash flow game, SYB games, and develop entrepreneurial training project for the professionals.

K. To set up the second class of the project design as the task Center

In order to complete the design of venture project, the teachers should make full use of network information technology, rely on the education information resources and the systematic teaching methods, and build the environment that Is made up of the theoretical teaching, information transmission and real-time consulting by the technical support of the occupation blog and QQ group. Then they obtain the effective teaching effect by the design of teaching contents and teaching process. The teachers may adjust the teaching website according to the feedback information on the network platform. In the process of interaction teaching ,the teachers may cultivate students' ability to analyze and solve problems by taking the method of case study, group competition, group cooperation, free operation to make the students active participate.

L. To set up the third class of the entrepreneurship Park oriented Venture project incubation

In the third class, we will create a true entrepreneurial environment, under which the student formate the team freedly, look for start-up projects, write business plans and prepare the human, material and financial resources for the business, and transformate entrepreneurial projects achievement. This activity will take business mentor system, and the tutor guidance the team.

\section{Summary}

By the teaching mode of "a combination of entrepreneurship and learning",we will achieve reforming and innovation of the teaching method in innovation and entrepreneurship education . we will take a series of reforms in teaching methods, practice teaching structure, teaching mode, teaching system and learning methods, and the ultimate realization of the ideas of practice teaching reform and innovation.

\section{Acknowledgements}

Fund project of Xi'an social science planning(16J163); Research project of the education and teaching re form in Xi'an International University(2015B01) 


\section{References}

[1] Elise Golan, Barry Krissoff, Linda Calvinand Kenneth Nelson. Traceability in the USA food supply: Economic Theory and Industry Studies[J].Agricultural Economic Report.2004,(03) .

[2] Mora C. , Menozzi D. Vertical Contractual Relations in the Italian Beef Supply Chain [J] . Agribusiness, 2005, 21(3) : 218-225

[3] ( Eds), Quality Assurance Risk Management and Environmental Control in Agriculture and Food Supply Networks [C] Bonn: Universitat Bonn-ILB, 2004

[4] Alfaro J. A . , R a’bade L. A. Traceability as a Strategic Tool to Improve Inventory Management: A Case Study in the Food Industry [ J . International Journal of Production Economics, 2009, 118( 1) : 102-106

[5]Galliano D. , R oux P. Organisational Motives and Spatial Effects in Internet Adoption and Intensity of Use: Evidence from FrenchIndustrial Firms [J]. The Annals of Regional Science, 2008, 42( 2) : 430-442

[6] Shufa Su. On Reforming of Specialty Construction and Practice Teaching of Logistics Engineerin [J] Forest engineering. 2014(03)

[7] Xuan Yi. Explore on the Mode of Entrepreneurship Education and Professional Education at the University in Our Country [J]. Innovation and Entrepreneurship Education. 2012(02)

[8] Hongji Jian. Explore On Present Situation, Problems and Countermeasures of Science and Technology Business Incubator Park of Panzhihua College Students [J]. Science and Technology Entrepreneurs. 2013(24) 